\title{
State-of-the-art Studies on the FRP-confined Concrete
}

\author{
Wenbin SUN \\ Faculty of Civil Engineering and Mechanics \\ Jiangsu University \\ Zhenjiang, China \\ E-mail: Sunwb1969@163.com
}

\author{
Ying LUO \\ Faculty of Civil Engineering and Mechanics \\ Jiangsu University \\ Zhenjiang, China \\ E-mail: luoying@mail.ujs.edu.cn
}

\begin{abstract}
The application of FRP in civil engineering has emerged as a popular method of column retrofitting and strengthening. Numerous experimental studies have proven that the confinement with FRP-wrap or tube encasement could enhance the strength, ductility and durability of concrete columns. The variation of each distinct experimental test result to its actual mean value is the general cause of modeling inaccuracy, and this appears to be a lack of consensus among the research community. This paper critically reviewed the current experimental studies with the emphasis on the revelation of the mechanical behavior of FRP-confined concrete and analytical study of its behavior. Lastly, some comments are made on the development trends of study on the mechanical behavior of FRP-confined concrete columns.
\end{abstract}

Keywords-FRP-confined concrete; mechanical behavior; experimental study; model

\section{INTRODUCTION}

It is well known that the lateral confinement of concrete can substantially enhance its compressive strength and ultimate axial strain [1-7]. There are several key material advantages and structural features that make FRP reinforcement a feasible option for concrete confinement. The high material modulus and tensile strength, automated fabrication, and engineered performance of FRP composites offer greater material efficiency and ease of application. The FRP materials are potential alternatives to steel reinforced concrete structures, particularly in severe environment conditions, due to their durability, watertight and electrochemical corrosion resistance [8-9].

Consequence to the significant research efforts on exploring the effectiveness of FRP confinement composites in strengthening concrete structures, a wide variety of behavioral issues have been examined, resulting to a large number of analytical models with varying levels of sophistication. It is common that their proposed models could not accurately predict the experimental test values obtained from other researchers. The variation of each distinct experimental test result to its actual mean value is the general cause of modeling inaccuracy, and this appears to be a lack of consensus among the research community.

This paper critically reviewed the current experimental studies with the emphasis on the revelation of the fundamental behavior of FRP-confined concrete. The evaluation of the fundamental confinement behavior was classified based on the following aspects: difference in between FRP-wrap and FRP tube confinement systems; variability of the type of FRP materials used for confinement reinforcement; compressive strength of unconfined concrete; cross-sectional geometry and confinement reinforcement arrangement; specimen scale and slenderness; amount of FRP confinement reinforcement.

\section{CONCRETE CONFINEMENT PARAMETERS}

This part presents the evaluation of current studies on FRP-confined concrete from the various confinement parameters, such as confinement methods, geometry properties, and material properties.

\section{A. FRP Wrap and Tube Encasement Confinement Systems}

FRP is wrapped around the surface of existing concrete columns to strengthen its structural performance, and this presents a retrofitting strategy. Although construction guidance is available for a better quality control of FRP products, manufacturing imperfections still happen in practice: (1) incompletely impregnated fibers will trap air bubbles in the laminates, (2) non-uniformly distribution of resin on fiber surface, (3) low compaction, poor fiber alignment and damaged fiber, and (4) unreliable control of resin cure. These factors induce residual strain and reduce the in-situ capacity of FRP materials [10]. Harries and Carey [11] had investigated the influence of adhesive bond on hoop rupture strain of FRP confining jacket, and it was observed that adhesive bond can reduce the value of FRP hoop rupture strain. The interfacial bond can also transfer a portion of axial stress from the concrete core to the FRP lateral reinforcement, and result the FRP jacket to be loaded in multi-axial directions and hence reduce the lateral confinement capacity [12]. Having loaded in flexural and stress concentration conditions, the low flexural stiffness of FRP materials lead to a premature failure of fiber, and rupture at stress much lower than the material ultimate strength.

A number of studies have been conducted using fibers aligned along a direction other than the hoop direction. Mirmiran and Shahawy [1] used fibers oriented at $\left[ \pm 15^{\circ}\right]$ from the hoop direction in their FRP tube encased concrete columns. In the study by Rochette and Labossiere [13], fibers oriented at $\left[ \pm 15 \% 0^{\circ}\right]$ were used to wrap square concrete cylinders. Pessiki et al. [6] employed $\left[0 \% 45^{\circ}\right]$ fibers to warp both small-scale and large-scale square and circular concrete columns. Fibers in both hoop and axial directions were used by Silva and Santos [14] to repair concrete columns. Fam and Rizkalla [15] and Fam et al. [16] 
studied filament wound FRP tube encased concrete columns. In their tubes, fibers in various directions and stacking sequences were utilized to provide both hoop confinement and axial reinforcement. Li et al. [10] tested on the fifteen coupon specimens which were prepared to experimentally determine the tensile strength of the FRP with fibers oriented at $0^{\circ}, 45^{\circ}$, and $90^{\circ}$ from the loading direction, and co-axial compression tests were conducted on the wrapped cylinders and control cylinders. It was found that the strength, ductility, and failure mode of FRP wrapped concrete cylinders depend on the fiber orientation and thickness. Fibers oriented at a certain angle in between the hoop direction and axial direction may result in strength lower than fibers along hoop or axial direction.

In the early of 1980s, the concept of FRP tube-encased concrete column was proposed by Fardis and Khalili [17]. Since no direct chemical bond applied in between the tube and concrete, desired loading pattern of the composites elements can be engineered during the prefabrication of the tubes. In order to attribute a full lateral confinement, fibers of the tube encasement can be oriented predominantly in hoop direction. Li et al. [18] had conducted experimental study on FRP tube-encased concrete columns to investigate the effect of concrete strength on column stress-strain behavior, compressive strength, flexural strength, ductility and interfacial bond strength of FRP tube-encased concrete columns.

\section{B. Types and Thickness of FRP Materials}

The selection of the type of FRP materials and the fiber thickness depends on several factors, such as the required enhancement in compressive strength, peak stress of unconfined concrete that subjected to FRP confinement, as well as the shape and dimension of concrete core. The fiber types that are commonly used in manufacturing the FRP laminates include CFRP (Carbon Fiber Reinforced Polymer), GFRP (Glass Fiber Reinforced Polymer), AFRP (Aramid Fiber Reinforced Polymer), and HFRP (Hybrid Fiber Reinforced Polymer).

Toutanji and Houssam [3], Saafi et al. [4], Fam and Rizkalla [8] Karbhari and Gao [19], and Becque et al. [20] had conducted extensive experimental study for cylinder specimens with a wide range of FRP with different modulus, fiber orientation and thickness, either for FRP-wrapped or tube-encased concrete columns. The intention of their studies was to quantify the influence of confinement stiffness on axial strength enhancement of columns. The lateral pressure generated by FRP confinement was found that to have direct influence on the stress-strain behavior of circular sections, and thus the rate of axial enhancement [21]. However, some researchers reported that the confinement stiffness has nonlinear influence on strength enhancement of confined concrete $[3-4,22]$.

\section{Shape and Geometries of Cross-Section}

Most of the current studies have been concerned on circular confined concrete columns. Therefore, number of confinement models has been developed to model the stress- strain behavior of circular confined concrete [3-5,8$9,17,19,22-26]$.

The rectilinear shape of confined columns was reported to have relatively less increase in strength and ductility compared to circular columns [27]. It is mainly due to the non-uniform distribution of confining pressure, provided by the FRP confinement that varies over the rectilinear concrete cross-section and resulting significant reduction in confinement effectiveness. In general, corner rounding of rectilinear sections can reduce the detrimental effect on FRP rupture strain at a sharp corner and to improve the confinement effectiveness [22]. Studies conducted by Mirmiran et al.[1] and Rochette and Labossiere [13] have shown that the confinement effectiveness is dependent not only on the sectional shape of columns, but also the stiffness of FRP confinement. It is also believed that, some other factors may influence the in-situ capacity of FRP materials due to the non-uniform confinement pressure attributed from non-circular sectional shape [28].

\section{Scale Effect}

Most of the current research reported that the specimen scale does not significantly affect the behavior of FRPconfined concrete [29]. Therefore, many studies have been carried out using relatively small-scale specimens. However, the small-scale specimens might conceal possible scale effects since the dilation properties of concrete could be influenced by specimen size [30]. At a relatively high level of confinement, scale effect could influence the confinement effectiveness of confined concrete [31]. It is therefore, modeling the behavior of full-scale columns based on smallscale experimental study may yield inaccurate result.

\section{E. Slenderness Effect}

Theriault et al. [30] and El Echary [32] have suggested that slenderness effect will reduce nominal axial strength of FRP-confined concrete columns. The effect of column slenderness has been studied by several researchers [33-34]. In analyzing the existing test data, Carey and Harries [31], Mirmiran et al [35] have isolated the specimens with great height-to-diameter ratio from their experimental test database to eliminate the slenderness effect on confinement effectiveness.

\section{F. Concrete Strength}

Berthet et al. [20] have reported the variation in concrete strength has no influence on confinement effectiveness for normal-strength concrete; but for high-strength concrete, the material efficiency of FRP confinement may be decreased. This was supported by the observation on lower structural efficiency of FRP materials in confining high-strength concrete compared to normal-strength concrete, and this is mainly due to the more brittle behavior of high-strength concrete [31]. The influence of concrete strength variation has been studied by some researchers [19, 36-37].

With the development of economy and technology the utilization of high strength concrete (HSC) in high rising buildings and bridges becomes more and more popular. The character of brittle failure is a main obstacle of this trend, 
especially in seismic areas. Zhao et al [38] have reported that the ductility of HSC columns strengthened with CFRP is significantly improved and the strength is also increased by some degree.

\section{G. Transverse Steel Reinforcement}

Zhu et al. [39] have reported that, most of the experimental studies associated with the analytical models do not account for internal transverse steel reinforcement, and this has been justified based on their experimental investigation. It is recommended that the influence of internal transverse or longitudinal steel reinforcement has to be explicitly considered in the development of confinement model, in order to eliminate the additional effect of steel reinforcement in FRP confinement [26]. For instance, Lam and Teng [9] have excluded the test data for specimens with steel reinforcement from their collection of test database.

\section{FRP MATERIALS}

In order to further improve the confinement model accuracy, some studies have been concerned with the ultimate conditions of FRP-confined concrete. The ultimate failure of FRP-confined concrete is usually characterized by the rupture of FRP materials associated with the ultimate tensile strain or stress of the FRP confining materials. Shahawy et al. [40] revealed that the actual FRP hoop rupture strains are considerably lower than those values obtained from manufacturer and material tensile tests. However, most of the researchers used the FRP hoop rupture strain values for their models directly obtained from data provided by manufacturer or flat coupons tensile tests. There are extensive experimental studies of FRP-confined concrete and reported that the fiber ultimate tensile strain generally could not be reached [5-6]. Therefore, some researchers have introduced a confinement parameter of FRP ultimate strain in their analytical models [3-4,41]. Lam and Teng [12] have suggested that the actual hoop rupture strain of FRP should be considered in order to better simulate the FRP-confined concrete. It is concluded that if the FRP rupture strain is assumed to be equivalent to the fiber ultimate tensile strain, none of the current models are able to model the specimen ultimate condition with reasonable accuracy.

\section{CuRRENT Stress-Strain Models}

Lam and Teng [22] have classified the current stressstrain models into two major categories, namely designoriented model and analysis-oriented model. The designoriented model predicts the concrete compressive strength, ultimate axial strain, as well as stress-strain response of FRPconfined concrete using simple closed-form equations based on direct evaluation and interpretation of experimental test data. However, for analysis-oriented model, stress-strain curves are generated rigorously using incremental and iterative numerical procedures associated with the interaction in between concrete and confining materials. The complexity of the incremental and iterative numerical processes prevent analysis-oriented models from directly use in design, whereas it is more suitable for numerical analysis such as nonlinear finite element analysis.
Models used to predict axial stress-strain behavior of steel-confined concrete have been developed empirically on the basis of extensive experimental studies. In some models, the ultimate FRP confined-concrete strength and the second branch of stress-strain curves have been adjusted as a function of confinement provided by lateral reinforcement ratio and concrete compressive strength. The simplicity of these models has made them popular to use in capacity calculations and sectional analysis. There is one important disadvantage of these models due to their lack of generality. For instance, the capability of these models is dependent on the types of collected experimental results. A number of studies have concerned with the development of non-linear finite element analysis (FEM) of FRP-confined concrete $[13,22]$. Adopting the FEM method, it is capable to predict the non-uniform stress-strain behavior of the unique dilation characteristics of concrete that confined by linear-elastic and non-yielding materials like FRP.

\section{SUMMARY}

Although significant research efforts during the past twenty years have been focused on FRP-confined concrete, and numerous analytical models have been presented to model the stress-strain behavior of FRP-confined concrete, yet several issues are worth to be discussed in the future:

Currently, there is a lack of understanding on the effect of concrete strength on the overall structural behavior, and the interface bonding strength in between FRP confinement and concrete core.

Most of the current experimental and analytical studies are focused on cylindrical confined-concrete columns which have uniformly distributed confinement pressure. In practice, typical concrete columns come in various shapes including circular, square, and rectangular which incorporate longitudinal and transverse steel reinforcements. It is therefore only limited experimental and analytical studies on non-circular FRP-confined concrete are conducted.

Some models were developed based on limited considerations such as limited range of confinement levels and limited numbers of FRP materials; hence the models do not exhibit flexibility to account for other confinement parameters.

The absence of a general standard to carry out experimental testing results in variation of test conditions and specimen design. There are many experimental studies were undertaken on small-scale FRP-confined concrete whereas only some testing were conducted on medium to large-scale specimens. However, the size effects could cause the scattering on the gross results, and most of the researchers do not account for the variation of specimen size.

\section{REFERENCES}

[1] A. Mirmiranand M. Shahawy, "Behavior of concrete columns confined by fiber composites," J. Struct. Eng., vol. 123, May. 1997, pp. 583-590.

[2] A. Mirmiran and M. Shahawy, "Dilation characteristics of confined concrete," Int. J. Mech. of Cohesive-Frictional Mat., vol. 2, Mar. 1997, pp. 237-249. 
[3] Toutanji and A. Houssam, "Stress-strain characteristics of concrete columns externally confined with advanced fiber composite sheets," ACI Mat. J., vol. 96, Mar. 1999, pp. 397-404.

[4] M. Saafi, Toutanji, A. Houssam and Z. Li, "Behavior of concrete columns confined with fiber reinforced Polymer tubes," ACI Struct J, vol. 96, May. 1999, pp. 500-508.

[5] Y. Xiao and H. Wu, "Compressive behavior of concrete confined by carbon fiber composite jackets,” J Mat. Civ. Eng., vol. 12, Feb. 2000, pp. 139-146.

[6] S. Pessiki and K. A. Harries, "The axial behavior of concrete confined with fiber reinforced composite jackets," J. Compos. Constr., vol. 5. Apr. 2001, pp. 237-245.

[7] J. G Teng and L. Lam, "Behavior and modeling of fiber reinforced polymer-confined concrete," J. Struct. Eng, vol. 130, Nov. 2004, pp. 1713-1723.

[8] A. Z. Fam and S. H. Rizkalla, "Confinement model for axially loaded concrete confined by circular fiber-reinforced polymer tubes," ACI Struct. J., vol. 98, Apr. 2001, pp. 451-461.

[9] L. Lam and J. G.Teng, "Strength models for FRP-confined concrete," J. Struct Eng, vol. 128, May. 2002, pp. 612-623.

[10] G. Q. Li, D. Maricherla, Singh K, et al., "Effect of fiber orientation on the structural behavior of FRP wrapped concrete cylinders," Compo. Struct., vol. 74, Aug. 2006, pp. 475-483.

[11] K. A. Harries and A.Carey, "Shape and 'gap' effects on the behavior of variably confined concrete," Cem. Concr. Res., vol. 33, Jun. 2002, pp. 881-890.

[12] L. Lam and J. G. Teng, "Design-oriented stress-strain model for FRP-confined concrete," Constr. Build. Mat., vol. 17, Jun. 2003, pp. 471-489.

[13] P. Rochette and P. Labossiere, "Axial testing of rectangular column models confined with composites," J. Compos. Constr., vol. 4, Aug. 2000, pp. 129-136.

[14] D. Silva and J. M. C. Santos, "Strengthening of axially loaded concrete cylinders by surface composites," Proc. of Int. Conf., A.A. Balkema Publishers, Nov. 2001, pp. 257-262.

[15] A. Z. Fam and S. H.Rizkalla, "Behavior of axially loaded concretefilled circular fiber-reinforced polymer tubes," ACI Struct J., vol. 98, Mar. 2001, pp. 280-289.

[16] A. Fam, M. Pando, G. Filz and S. Rizkalla, "Precast piles for route 40 bridge in Virginia using concrete filled FRP tubes," PCI J.,vol. 48, May. 2003, pp. 32-45.

[17] M. N. Fardis and H. Khalili, "FRP-encased Concrete as a Structural Material," Mag. Concr. Res., vol. 34, Dec. 1982, pp. 191-202.

[18] G. Q, Li, S. Torres, W. Alaywan, et al., "Experimental study of FRP tube-encased concrete columns," J. Compos. Mat., vol. 39, Dec. 2004, pp. 1131-1145.

[19] V. M. Karbhari and Y. Gao, "Composite jacketed concrete under uniaxial compression-verification of simple design equations," J. Mat. Civ. Eng, vol. 9, Apr. 1997, pp. 185-193.

[20] J. Becque, A. K. Patnaik and S. H. Rizkalla, "Analytical models for concrete confined with FRP tubes," J. Compos. Constr., vol. 7, Jan. 2003, pp. 31-38.

[21] J. F. Berthet, E. Ferrier and P. Hamelin, "Compressive behavior of concrete externally confined by composite jackets. Part A: experimental study," Constr. Build. Mat., vol. 19, Apr. 2005, pp. 223232.

[22] M. Samaan, A. Mirmiran and M. Sahawy, "Model of concrete confined by fiber composites," J. Struct. Eng., vol. 124, Sep. 1998, pp. 1025-1031.
[23] M. Demers and K. W. Neale, "Confinement of reinforced concrete columns with fiber reinforced composite sheets-An experimental study," Can. J. Civ. Eng., vol. 26, Feb. 1999, pp. 226-241.

[24] K. Miyauchi, S. Inoue, T. Kuroda, et al., "Strengthening effects with carbon fiber sheet for concrete column," Proc Jpn Concr Inst, vol. 21, Mar. 1999, pp. 1453-1458.

[25] H. J. Lin and C. I. Liao, "Compressive strength of reinforced concrete column confined by composite material," J. Compos. Struct., vol. 65 , Aug. 2004, pp. 239-250.

[26] A. Ilki and N. Kumbasar, "Compressive behavior of carbon fibre composite jacketed concrete with circular and non-circular crosssections," J. Earthquake Eng., vol. 7, Mar. 2003, pp. 38-406.

[27] M. Maalej, S. Tanwongsval and P. Paramasivam, "Modelling of rectangular RC columns strengthened with FRP," Cem. Concr. Compos., vol. 25, Feb. 2003, pp. 263-276.

[28] Z. Yan, C. P. Pantelides and L. D. Reaveley, "Shape modification with expansive cement concrete for confinement with FRP composites," FRPRCS-7, 2006, pp.1047-1066.

[29] S. H. Ahmad and S. P. Shah, "Stress-strain curves of concrete confined by spiral reinforcement," AU J., vol. 79, Jun. 1982, pp.484490.

[30] M. Theriault, K. W. Neale and S. Claude, "Fiber Reinforced PolymerConfined Circular Concrete Columns: Investigation of size and slenderness effects," J. Compos. Constr., vol. 8, Apr. 2004, pp. 323331.

[31] S. A. Carey and K. A. Harries, "Axial behavior and modeling of confined small, medium, and large scale circular sections with carbon fiber-reinforced polymer jackets," ACI Struct. J., vol. 102, Apr. 2005, pp. 596-604.

[32] El Echary, "Length effect on concrete filled FRP tubes using acoustic emission," Orlando: University of Central Florida, 1997.

[33] M. Theriault, S. Claude and K. W. Neale, "Effect of size and slenderness ratio on the behavior of FRP-wrapped columns,". FRPRCS-5, Cambridge U.K., Vol. 2, 2001, pp. 765-772.

[34] A. Mirmiran, M. Shahawy and T. Beitleman. "Slenderness Limit for hybrid FRP-concrete columns," J. Compos. Constr., vol. 5, Jan. 2001, pp. 26-34.

[35] Mirmiran A, Shahawy M, Samaan M, El Echary. Effect of column parameters on FRP-confined concrete. J. Compos. Constr., 1998, 2(4): 175-185.

[36] T. G. Harmon and K. T. Slattery, "Advanced composite confinement of concrete," Proc. of 1st Int. Conf. on Advanced Compos. Mat. In Bridge and Struct. Sherbrooke, Canada, 1992, pp.299-306.

[37] K. Miyauchi, S. Nishibayashi and S. Inoue, "Estimation of strengthening effects with carbon fiber for concrete column," Proc. 3rd Int. Symposium on Non-metallic (FRP) Reinforcement for Concr. Struct., Japan, 1997, pp. 217-224.

[38] T. Zhao, J. Xie, M. G. Liu, et al., "Study on high strength concrete confined by continuous carbon fiber sheet," Transactions of Tianjin Uni., vol. 8, Jan. 2002, pp. 12-15.

[39] Z. Zhu, L. Ahmad and A. Mirmiran, "Effect of column parameters on axial compression behavior of concrete-filled FRP tubes," Advances in Struct. Eng., vol. 8, Apr. 2005, pp. 443-449.

[40] M. Shahawy, A. Mirmiran and T. Beitelman, "Tests and modeling of carbon-wrapped concrete columns," J. Compos., vol. 31, Oct. 2000, pp. $471-480$.

[41] M. R. Spoelstra and G. Monti, "FRP-confined concrete model," J. Compos. Constr., vol. 3, Mar. 1999, pp. 143-150. 